\title{
Introduction to Measurement with Theory
}

by

\author{
William A. Barnett \\ Department of Economics \\ University of Kansas \\ W. Erwin Diewert \\ Department of Economics \\ University of British Columbia \\ and \\ Arnold Zellner \\ Graduate School of Business \\ University of Chicago
}

\begin{abstract}
This paper is the introduction to the forthcoming Macroeconomic Dynamics Special Issue on Measurement with Theory. The Guest Editors of the special issue are William A. Barnett, W. Erwin Diewert, Shigeru Iwata, and Arnold Zellner. The authors of this detailed introduction and commentary are William A. Barnett, W. Erwin Diewert, and Arnold Zellner. The included papers are part of a larger initiative to promote measurement with theory in economics.
\end{abstract}

Keywords: $\quad$ Measurement; index number theory; aggregation theory. 


\section{Introduction}

This special issue of Macroeconomic Dynamics is devoted to papers that address various measurement problems while drawing on economic theory in a manner that is theoretically internally consistent at all relevant levels of aggregation and relative to the models within which the measured data are used. The special issue is part of a larger initiative to promote "measurement with theory," as opposed to the well known "measurement without theory" and "theory without measurement." The eight papers in this special issue can be grouped into three general classes:

- Papers that address some of the problems associated with making international comparisons of welfare and productivity;

- Papers that draw primarily on production theory and

- Papers that draw primarily on consumer theory.

Of course, there are some papers that could be slotted into more than one of the above categories; in particular, the first two papers in the international comparisons category draw on consumer theory while the third paper in this category draws on producer theory. The second paper in the production theory category uses both consumer theory regarding occupational choice and producer theory regarding financial intermediation. 
Sections 2, 3 and 4 below will be devoted to brief descriptions of the papers which appear in each of the above three categories.

\section{International Comparisons of Prices, Quantities and Productivity}

There are three papers in this special issue that make international comparisons. The first paper is by Robert Feenstra, Hong Ma and Prasada Rao (2009). Their paper addresses the following problem. Suppose the World Bank or some other organization undertakes periodic comparisons of final demand prices every 5 or 10 years so that estimates of real GDP and its components can be made across countries for the year when the International Comparison Project (ICP) constructs its price estimates. Then national price and expenditure data can be used to construct comparable estimates of real GDP across time and countries. The problem with these comparisons is that they change (sometimes very dramatically) every time a new cross sectional comparison is made; i.e., the resulting panel data are not consistent across time and space. The Feenstra-Ma-Rao paper (henceforth FMR) provides a solution to this problem by extending the methodology developed by Neary (2004) who makes a single cross sectional comparison to the case where there are two sets of cross sectional data.

In order to explain the FMR methodology, it will be useful to first explain Neary’s methodology. Neary (2004) draws on an early method for making international 
comparisons that was suggested by Geary (1957). ${ }^{1}$ Since Neary’s method for making international comparisons is a modification of Geary’s method, we will explain Geary's method first. Suppose we have data for some time period on the prices (in national currencies but in comparable units of measurement) for $\mathrm{N}$ commodity groups and $\mathrm{J}$ countries, $p_{j} \equiv\left[p_{j 1}, \ldots, p_{j N}\right]$, where $p_{j}$ is the country $j$ price vector and $q_{j} \equiv\left[q_{j 1}, \ldots, q_{j N}\right]$ is the corresponding country $\mathrm{j}$ quantity vector for $\mathrm{j}=1, \ldots, \mathrm{J}$. Thus total expenditure on these commodities for country $\mathrm{j}$ in the time period under consideration is the inner product of the country $\mathrm{j}$ price and quantity vectors, which we denote by $\mathrm{p}_{\mathrm{j}} \cdot \mathrm{q}_{\mathrm{j}}$ for $\mathrm{j}=1, \ldots, \mathrm{J}$. The Geary Khamis or GK vector of international reference prices is the vector $\pi \equiv\left[\pi_{1}, \ldots, \pi_{N}\right]$ and the vector of true exchange rates $^{2}$ is the vector $\varepsilon \equiv\left[\varepsilon_{1}, \ldots, \varepsilon_{\mathrm{J}}\right]$. The components of these two vectors are the solution to the following set of equations: ${ }^{3}$

$$
\begin{array}{ll}
\pi_{\mathrm{n}}=\sum_{\mathrm{j}=1}^{\mathrm{J}} \varepsilon_{\mathrm{j}} \mathrm{p}_{\mathrm{jn}} \mathrm{q}_{\mathrm{jn}} / \sum_{\mathrm{j}=1}^{\mathrm{J}} \mathrm{q}_{\mathrm{jn}} ; & \mathrm{n}=1, \ldots, \mathrm{N} ; \\
\varepsilon_{\mathrm{j}}=\pi \cdot \mathrm{q}_{\mathrm{j}} / \mathrm{p}_{\mathrm{j}} \cdot \mathrm{q}_{\mathrm{j}} ; & \mathrm{j}=1, \ldots, \mathrm{J} .
\end{array}
$$

\footnotetext{
${ }^{1}$ For surveys of the early methods used to make international comparisons that rely on index number theory, see Diewert (1988) (1999) and Balk (1996). In this literature, Geary's method is known as the Geary (1957) Khamis (1972) method (the GK method) because Khamis provided a rigorous proof of the existence of a solution to Geary's equations.

${ }^{2}$ Neary $(2004 ; 1413)$ uses this terminology. In the international comparisons literature, the country j true exchange rate $\varepsilon_{\mathrm{j}}$ is usually replaced by its reciprocal, the country j Purchasing Power Parity.

${ }^{3}$ The system of equations (1) and (2) only determines $\pi$ and $\varepsilon$ up to a positive scalar multiple. Thus we require an additional normalization on (1) and (2) such as $\varepsilon_{1}=1$ or $\pi_{1}=1$ in order to obtain a unique solution.
} 
Once the reference prices $\pi$ have been determined, the GK quantity aggregates, $\mathrm{Q}_{\mathrm{j}}$ for $\mathrm{j}=1, \ldots, \mathrm{J}$, are defined as the inner product of the international price vector $\pi$ with the country j quantity vector, $\mathrm{q}_{\mathrm{j}}$; i.e., we have:

$$
\mathrm{Q}_{\mathrm{j}} \equiv \pi \cdot \mathrm{q}_{\mathrm{j}} ; \quad \mathrm{j}=1, \ldots, \mathrm{J}
$$

Neary’s modification of Geary’s method works as follows. First, Neary restricted himself to making comparisons of consumption across countries and so consumer theory can be applied to these comparisons. Second, Neary assumed that per capita consumption data across countries can be rationalized by assuming common (nonhomothetic) tastes across countries. ${ }^{4}$ Thus using the per capita consumption data for 11 commodity groups for 60 countries for the year 1980 that was constructed by the International Comparisons Project (ICP), Neary estimated a flexible functional form $\mathrm{e}(\mathrm{p}, \mathrm{u})$ for a consumer expenditure function. ${ }^{5}$ Once the expenditure function has been estimated, country utility levels $\mathrm{u}_{\mathrm{j}}$ can be calculated by solving the following equations for $u_{j}$ :

$$
\mathrm{e}\left(\mathrm{p}_{\mathrm{j}}, \mathrm{u}_{\mathrm{j}}\right)=\mathrm{p}_{\mathrm{j}} \cdot \mathrm{q}_{\mathrm{j}} ; \quad \mathrm{j}=1, \ldots, \mathrm{J} .
$$

\footnotetext{
${ }^{4}$ Thus $\mathrm{p}_{\mathrm{j}}$ is now a vector of consumer prices for country $\mathrm{j}$ and $\mathrm{q}_{\mathrm{j}}$ is the corresponding per capita consumption vector.

${ }^{5}$ Neary $(2004 ; 1420)$ estimated both the AIDS model of Deaton and Muellbauer (1980) and the more flexible QUAIDS model of Banks, Blundell and Lewbel (1997). Neary (2004; 1422) noted that his AIDS and QUAIDS models were visually indistinguishable in his Figure 1.
} 
Given that the expenditure function e is known and the country utility levels $u_{j}$ have been determined via equations (4), we could choose any reference price vector $\pi$ and use following money metric utility ${ }^{6}$ estimates $U_{j}(\pi)$ in order to obtain a theoretically consistent cardinal measure of the per capita consumption of country $\mathrm{j}$ in real terms:

$$
\mathrm{U}_{\mathrm{j}}(\pi) \equiv \mathrm{e}\left(\pi, \mathrm{u}_{\mathrm{j}}\right) ; \quad \mathrm{j}=1, \ldots, \mathrm{J}
$$

The family of cardinal utility measures defined by (5) is very closely related to the family of Allen (1949) quantity indexes of per capita consumption between countries j and k:

$$
\mathrm{Q}_{\mathrm{A}}\left(\pi, \mathrm{u}_{\mathrm{j}}, \mathrm{u}_{\mathrm{k}}\right) \equiv \mathrm{e}\left(\pi, \mathrm{u}_{\mathrm{k}}\right) / \mathrm{e}\left(\pi, \mathrm{u}_{\mathrm{j}}\right) ; \quad \mathrm{j}, \mathrm{k}=1, \ldots, \mathrm{J} .
$$

Thus for each choice of a reference price vector $\pi$, one can define consistent measures of the per capita consumption of countries in the cross sectional comparison using (5) and the Allen indexes defined by (6) simply take ratios of the cardinal measures defined by (5).

Basically, Neary (2004) used the per capita measures defined by (5) (or a normalization of these measures) in order to rank the per capita consumption

\footnotetext{
${ }^{6}$ This terminology is due to Samuelson $(1974 ;$ 1262) but the basic idea is due to Hicks (1941-42). Basically, this method cardinalizes utility by using the distance from the origin of a family of parallel budget hyperplanes (indexed by the reference price vector) where each budget hyperplane is just tangent to an indifference surface.
} 
expenditures of the 60 countries in his 1980 sample of countries. However, we now encounter the interesting problem of how exactly should the international vector of reference prices $\pi$ be chosen?

Neary used the $\pi$ solution to the following equations, which are related to the original Geary equations, (1) and (2): ${ }^{7}$

$$
\begin{array}{rlr}
\pi_{\mathrm{n}} & =\sum_{\mathrm{j}=1}{ }^{\mathrm{J}} \varepsilon_{\mathrm{j}} \mathrm{p}_{\mathrm{jn}} \mathrm{q}_{\mathrm{jn}} / \sum_{\mathrm{j}=1}^{\mathrm{J}} \partial \mathrm{e}\left(\pi, \mathrm{u}_{\mathrm{j}}\right) / \partial \pi_{\mathrm{n}} ; \quad \mathrm{n}=1, \ldots, \mathrm{N} ; \\
\varepsilon_{\mathrm{j}} & =\mathrm{e}\left(\pi, \mathrm{u}_{\mathrm{j}}\right) / \mathrm{p}_{\mathrm{j}} \cdot \mathrm{q}_{\mathrm{j}} & \mathrm{j}=1, \ldots, \mathrm{J} . \\
& =\mathrm{e}\left(\pi, \mathrm{u}_{\mathrm{j}}\right) / \mathrm{e}\left(\mathrm{p}_{\mathrm{j}}, \mathrm{u}_{\mathrm{j}}\right) .
\end{array}
$$

Once the vector of Neary international reference prices $\pi$ has been determined by solving (7) and (8), consistent theoretical measures of country real per capita consumption, $\mathrm{U}_{\mathrm{j}}(\pi)$, can be obtained by using the estimated expenditure function e and definitions (5) for this $\pi$. Neary $(2004 ; 1417)$ called his real consumption estimates Geary-Allen true indexes of real income and he termed his overall multilateral method for making international comparisons the Geary Allen International Accounts (GAIA). Since multilateral methods are usually named after the pioneers who invented the method and established the properties of the method, it seems appropriate to call Neary's multilateral method the Geary Neary (GN) method.

\footnotetext{
${ }^{7}$ As in the GK system of equations, Neary shows that one additional normalization on the components of $\pi$ and $\varepsilon$ is required in order to obtain a unique solution to (7) and (8).
} 
Now we are in a position to evaluate the contribution of Feenstra, Ma and Rao. They too estimate a nonhomothetic flexible functional form for an expenditure function (the AIDS model) but they use the per capita expenditure data pertaining to two ICP price and quantity comparisons: the comparisons for 1980 and for 1996. They used Neary’s data and commodity classification for 1980 and aggregated the ICP data for the 1996 round of international comparisons to match Neary's commodity classification. They ended up with a consistent data set for 48 countries $^{8}$ which appeared in both the 1980 and 1996 data sets. Once the AIDS expenditure function was estimated, FMR used the methodology illustrated by equations (4) and (5) above in order to construct estimates of per capita real consumption for 48 countries for the years 1980 and 1996; i.e., they succeeded in their goal of obtaining consistent international comparisons of per capita “income” over time and space.

FMR also raise some interesting issues that have not been discussed in the literature that are centered around Neary’s nonhomothetic estimation methodology such as: what are the "right" reference prices $\pi$ to use in equations (5), which provide cardinal estimates of per capita consumption? Neary simply assumed that his GAIA reference prices constructed by solving equations (7) and (8) were the "right” reference prices and did not discuss the arbitrariness inherent in this choice. FMR experiment with alternative choices for the reference prices $\pi$. Three of their choices are Neary's GAIA reference

\footnotetext{
${ }^{8}$ Their analysis does rest on the assumption that the commodity units are comparable in the two ICP rounds, an assumption that is only approximately correct.
} 
prices, US prices ${ }^{9}$ and the unweighted geometric mean of all 96 (48 countries times 2 observations) country prices. Of course, the ordinal ranking of per capita consumption across countries should not depend on the choice of $\pi$ but the results tabled in the paper by FMR show that the cardinal ranking of country observations does change considerably as $\pi$ changes. The fact that the cardinal estimates of per capita consumption change considerably as $\pi$ changes means that it is necessary to debate what the "right" choice of $\pi$ is. From the viewpoint of any single country $\mathrm{j}$, the most meaningful choice of $\pi$ would be $\mathrm{p}_{\mathrm{j}}$, country j's price vector. However, in the present context, we have two country $\mathrm{j}$ price vectors, say $\mathrm{p}_{\mathrm{j}}{ }^{1}$ and $\mathrm{p}_{\mathrm{j}}{ }^{2}$, representing the country $\mathrm{j}$ price vectors for 1980 and 1996 respectively. One could argue that the 1996 price vector (or more generally the last price vector in the sample) is the preferred choice between $\mathrm{p}_{\mathrm{j}}{ }^{1}$ and $\mathrm{p}_{\mathrm{j}}{ }^{2}$, since comparing the relative size of country budget sets in the present will be easier to accomplish if the most current set of country prices are used in the per capita consumption comparisons defined by (5) above. One could also argue that it would be more appropriate to choose reference prices for the country under consideration that are representative of the structure of relative prices for the entire sample period and this would lead us to set the preferred country $\mathrm{j}$ reference prices, $\pi_{\mathrm{j}} \equiv\left[\pi_{\mathrm{j} 1}, \ldots, \pi_{\mathrm{jN}}\right]$, equal to the geometric mean of the two country price vectors, $\left[\left(\mathrm{p}_{\mathrm{j} 1}{ }^{1} \mathrm{p}_{\mathrm{j} 1}{ }^{2}\right)^{1 / 2}, \ldots,\left(\mathrm{p}_{\mathrm{jN}}{ }^{1} \mathrm{p}_{\mathrm{jN}}{ }^{2}\right)^{1 / 2}\right] .{ }^{10}$ Using this choice $\pi_{\mathrm{j}}$ for $\pi$, country j's preferred set of per capita real consumption estimates could be defined as follows:

$$
\mathrm{U}_{\mathrm{k}}^{1}\left(\pi_{\mathrm{j}}\right) \equiv \mathrm{e}\left(\pi_{\mathrm{j}}, \mathrm{u}_{\mathrm{k}}^{1}\right) ; \mathrm{U}_{\mathrm{k}}^{2}\left(\pi_{\mathrm{j}}\right) \equiv \mathrm{e}\left(\pi_{\mathrm{j}}, \mathrm{u}_{\mathrm{k}}^{2}\right) \quad \mathrm{k}=1, \ldots, \mathrm{J} .
$$

\footnotetext{
${ }^{9}$ The components of the US $\pi$ are the geometric means of the 1980 and 1996 US prices for each of the 11 components of consumption.

${ }^{10}$ FMR use this set of country reference prices as building blocks in some of their comparisons.
} 
where $u_{k}{ }^{t}$ is country $k$ 's estimated utility level for year that results from the econometric estimation of the expenditure function e over the panel data set. Thus instead of a single set of cross country comparisons, the above suggested methodology would lead to a set of J cross country comparisons, one for each country being compared.

Of course, for many purposes, a single ranking of per capita “incomes” is required and so in the end, the J rankings defined by (9) will have to be averaged. Note that we are now in exactly the same situation that occurs when normal bilateral index number theory is applied in a multilateral context; i.e., a superlative bilateral index number formula can be used in order to generate estimates of per capita consumption using country $\mathrm{j}$ as the base country and this leads to $\mathrm{J}$ separate "star" rankings of real consumption. These separate measures are then averaged in order to obtain a final single ranking. The simplest way to average the individual star rankings is to take their equally weighted geometric average. If the superlative index number formula is the Fisher (1922) ideal quantity index ${ }^{11}$, then the resulting multilateral method is due to Gini (1931) and it is known as the EKS or GEKS multilateral method. Note that this method of weighting the separate "star" estimates is a democratic method of weighting; i.e., each country gets the same weight in the geometric mean of the separate country estimates. It is also possible to weight according to the relative size of each country (this is known as plutocratic weighting $^{12}$ ), but in the present context, democratic weighting seems more

\footnotetext{
${ }^{11}$ Caves, Christensen and Diewert (1982) applied this method using the Törnqvist Theil bilateral quantity index as their bilateral index.

${ }^{12}$ See Diewert (1988; 71) (1999) who introduced this terminology in the multilateral context.
} 
appropriate. FMR did not calculate the country specific estimates of real per capita consumption defined by (9) or take the geometric average of these estimates but we conjecture that this geometric average of the country estimates will generally be close to GEKS or Caves, Christensen and Diewert (1982) estimates based on traditional multilateral index number theory, (which does not use econometrics).

In addition to generalizing Neary’s method to a panel data context, Feenstra, Ma and Rao have several other very interesting results. In particular, they show (for both AIDS and translog nonhomothetic preferences) how to generate easily Allen quantity indexes of the type defined by (6) above for arbitrary reference price vectors $\pi$ using only information on the subset of parameters in these functional forms that are related to nonunitary income elasticities. These results should be of general interest to econometricians who estimate systems of consumer demand equations.

The second paper dealing with international comparisons in this special issue is by Robert Hill and Peter Hill (2009). Their paper explains the new methodology that was used in the 2005 International Comparison Program (ICP) that compared the relative price levels and GDP levels across 146 countries. ${ }^{13}$ In this round of the ICP, the world was divided into 5 regions: OECD and CIS countries, Africa, South America, Asia Pacific and West Asia. What is new in this round compared to previous rounds of the

\footnotetext{
${ }^{13}$ The 2005 ICP round was sponsored by the World Bank and other national and international statistical agencies. The final results of this round of GDP comparisons were released in February, 2008; see the World Bank (2008). The various ICP rounds play a very important role in the construction of the Penn World Tables, which are heavily utilized by many development and macro economists.
} 
ICP is that each region was allowed to develop its own product list and collect prices on this list for countries in the region. The regions were then linked using another separate product list and 18 countries across the 6 regions collected prices for products on this list and this information was used to link prices and quantities across the regions. Hill and Hill provide a comprehensive review of the new methodology that was used in ICP 2005. Their methodological review covers three topics:

- The construction of price indexes at the basic heading level;

- The construction of price indexes between countries within one of the five regions and

- The linking of the country comparisons across regions.

Hill and Hill are well qualified to describe the new methodological developments in the ICP since Peter Hill (2007) wrote all of the theory chapters in World Bank's methodological Handbook and Robert Hill (1997) (1999) (2001) (2004) has written numerous papers on multilateral index number theory. ${ }^{14}$

Hill and Hill look ahead to the next round of the ICP and make an interesting new methodological suggestion that is a variant of Robert Hill's (1999) (2001) (2004) minimum spanning tree methodology for making international comparisons. Based on a

\footnotetext{
${ }^{14}$ The World Bank's (2008) release of the ICP 2005 results did not describe the methodology used in the comparison. The theoretical chapters in the World Bank’s Handbook written by Peter Hill (2007) did not describe all of the methodology actually used in the final comparison. Hence the paper by Hill and Hill is particularly valuable in describing the actual methodology used in some of the problem areas. For additional methodological material on ICP 2005, see Diewert (2008) and Deaton and Heston (2008).
} 
suggestion by Diewert, they suggest that countries could be broken up into two groups: those with well funded statistical offices and those with less well funded offices. The first group of countries would be labeled as core countries and Hill's spanning tree methodology would be applied to only the core countries initially. ${ }^{15}$ The remaining countries would be linked to the initial core country tree by using an appropriate similarity measure for the structure of relative prices in each noncore country as compared to each country in the core group of countries. Thus suppose that there are C countries in the core group of countries and $\mathrm{N}$ countries in the noncore group. Denote the vector of basic heading prices for a core country c by $\mathrm{p}^{\mathrm{c}}$ for $\mathrm{c}=1, \ldots, \mathrm{C}$ and for a noncore country $n$ by $P^{n}$ for $n=1, \ldots, N$. Suppose further that a suitable measure of relative price dissimilarity, $\mathrm{s}(\mathrm{p}, \mathrm{P})$, has been chosen. ${ }^{16}$ Let $\mathrm{n}$ be an arbitrary noncore country and consider the following minimization problem:

$$
\min \left\{s\left(\mathrm{p}^{\mathrm{c}}, \mathrm{P}^{\mathrm{n}}\right): \mathrm{c}=1, \ldots, \mathrm{C}\right\}
$$

Suppose that core country c(n) solves the above minimization problem, so that the structure of relative prices in the core country $c(n)$ is the most similar to the structure of relative prices in the noncore country $n .{ }^{17}$ Then we link country $n$ to the core country c(n) using a superlative index number formula, such as the Fisher (1922) ideal formula.

\footnotetext{
${ }^{15}$ Alternatively, the initial set of core country comparisons could be obtained using the GEKS method.

${ }^{16}$ If $\mathrm{p}$ is proportional to $\mathrm{P}$, then $\mathrm{s}(\mathrm{p}, \mathrm{P})=0$ and if $\mathrm{p}$ is not proportional to $\mathrm{P}$, then $\mathrm{s}(\mathrm{p}, \mathrm{P})>0$. Thus the dissimilarity measure is analogous to a distance function in the mathematics literature. For additional material on the properties of dissimilarity measures, see Diewert (2009).

${ }^{17}$ If more than one country c is a solution to (10), then any of these solution countries could be taken as the link of country $n$ to the core spanning tree. Alternatively, all of the solution countries could be used as links to the core spanning tree and a geometric average of the resulting links could be taken.
} 
Thus there are $\mathrm{N}$ simple minimization problems of the form (10) to be solved: one for each noncore country. When all of the problems have been solved, all of the noncore countries will be linked to the core spanning tree. The resulting overall spanning tree will have the property that none of the noncore countries will have a large influence in the overall spanning tree (and noncore countries will be linked to core countries which have the most similar structure of relative prices).

The paper by Robert Inklaar and Marcel Timmer (2009) is our third paper that deals with international comparisons. However, this paper deals with comparison of industry levels of output, input and productivity across countries rather than comparisons of consumption or final demand, which was the focus of the first two papers.

The basic question that Inklaar and Timmer ask is whether productivity levels are converging across OECD countries over time. In order to address this question, the authors developed a new industry level data base for 20 OECD countries over the years 1970-2005. The authors combined the EU KLEMS Growth accounting database with their GGDC Productivity Level database. This second database provides productivity level comparisons for 20 OECD countries at a detailed industry level for the benchmark year, 1997. Then EU KLEMS database was then used to extrapolate this benchmark through time from 1970 to 2005. This was done at a detailed industry level. Modern 
production theory using the user cost of capital and superlative indexes was used in constructing their data base. ${ }^{18}$

Inklaar and Timmer find that Bernard and Jones (1996) were basically right: patterns of convergence in a set of advanced OECD countries differ considerably across sectors. Since the 1970s, Inklaar and Timmer find a process of steady convergence in market services but they find little evidence for convergence in manufacturing or other goods-producing industries. Moreover, when they analyzed convergence at a more detailed industry level using a dataset of 24 industries, they found that the patterns of convergence and divergence since 1980 are very different and far from homogenous even within industry groups such as market services. ${ }^{19}$

\section{Production Theory}

The special issue contains two papers relevant to measurement in a production context. The paper by Bert Balk (2009a) in this special issue looks at the relationship between measures of productivity growth that are based on either a gross output framework or on a value added framework. If $\mathrm{Y}^{\mathrm{t}}$ denotes the aggregate output of a production unit in period $\mathrm{t}$ and $\mathrm{X}^{\mathrm{t}}$ denotes the corresponding aggregate input used by that

\footnotetext{
${ }^{18}$ This literature dates back to the pioneering contributions of Jorgenson and Griliches (1967). Later, their continuous time methodology using Divisia indexes was adapted to discrete time and the use of superlative indexes by Diewert (1976), Caves, Christensen and Diewert (1982) and Diewert and Morrison (1986).

${ }^{19}$ One limitation of their analysis should be kept in mind: the EUKLEMS database does not have the services of land or inventories included as inputs. Thus results for land intensive sectors such as agriculture or for inventory intensive sectors such as retailing may be less reliable than results for other sectors.
} 
unit in period t, the period $t$ (Total Factor) Productivity of the unit is simply the ratio $\mathrm{Y}^{\mathrm{t}} / \mathrm{X}^{\mathrm{t}}$. The corresponding period t TFP growth of the unit, $\mathrm{TFPG}^{\mathrm{t}}$, is defined as the ratio of the unit's period t TFP to the corresponding period t-1 TFP:

$$
\mathrm{TFPG}^{\mathrm{t}} \equiv\left[\mathrm{Y}^{\mathrm{t}} / \mathrm{X}^{\mathrm{t}}\right] /\left[\mathrm{Y}^{\mathrm{t}-1} / \mathrm{X}^{\mathrm{t}-1}\right]=\left[\mathrm{Y}^{\mathrm{t}} / \mathrm{Y}^{\mathrm{t}-1}\right] /\left[\mathrm{X}^{\mathrm{t}} / \mathrm{X}^{\mathrm{t}-1}\right]
$$

The second expression in (11) indicates how TFP growth can be computed in practice: aggregate output growth $\mathrm{Y}^{\mathrm{t}} / \mathrm{Y}^{\mathrm{t}-1}$ can be replaced by a bilateral quantity index, $\mathrm{Q}\left(\mathrm{p}^{\mathrm{t}-1}, \mathrm{p}^{\mathrm{t}}, \mathrm{y}^{\mathrm{t}-1} \cdot \mathrm{y}^{\mathrm{t}}\right)$, where $\mathrm{p}^{\mathrm{t}}$ and $\mathrm{y}^{\mathrm{t}}$ are the period t output price and quantity vectors for the production unit, and aggregate input growth $\mathrm{X}^{\mathrm{t}} / \mathrm{X}^{\mathrm{t}-1}$ can be replaced by a bilateral quantity index, $\mathrm{Q}^{*}\left(\mathrm{w}^{\mathrm{t}-1}, \mathrm{w}^{\mathrm{t}}, \mathrm{x}^{\mathrm{t}-1} \cdot \mathrm{x}^{\mathrm{t}}\right)$, where $\mathrm{w}^{\mathrm{t}}$ and $\mathrm{x}^{\mathrm{t}}$ are the period $\mathrm{t}$ input price and quantity vectors for the production unit. ${ }^{20}$ The difference between the gross output and value added approaches to measuring TFP growth can now be explained. In the gross output framework, $\mathrm{Q}\left(\mathrm{p}^{\mathrm{t}-1}, \mathrm{p}^{\mathrm{t}}, \mathrm{y}^{\mathrm{t}-1} \cdot \mathrm{y}^{\mathrm{t}}\right)$ is an aggregate growth rate for all of the outputs produced by the production unit and $\mathrm{Q}^{*}\left(\mathrm{w}^{\mathrm{t}-1}, \mathrm{w}^{\mathrm{t}}, \mathrm{x}^{\mathrm{t}-1} \cdot \mathrm{x}^{\mathrm{t}}\right)$ is an aggregate growth rate for all of the primary and intermediate inputs used by the production unit, whereas in the value added framework, $\mathrm{Q}\left(\mathrm{p}^{\mathrm{t}-1}, \mathrm{p}^{\mathrm{t}}, \mathrm{y}^{\mathrm{t}-1} \cdot \mathrm{y}^{\mathrm{t}}\right)$ is an aggregate growth rate for all of the outputs produced by the production unit less the intermediate inputs used by the unit ${ }^{21}$ and $\mathrm{Q}^{*}\left(\mathrm{w}^{\mathrm{t}-1}, \mathrm{w}^{\mathrm{t}}, \mathrm{x}^{\mathrm{t}-1} \cdot \mathrm{x}^{\mathrm{t}}\right)$ is an aggregate growth rate for just the primary inputs used by the

${ }^{20}$ For additional material on basic productivity analysis, see Jorgenson and Griliches (1967), Diewert (1992b), Balk (2003) and Diewert and Nakamura (2003).

${ }^{21}$ In the value added framework, the vector $y^{t}$ consists of all of the outputs produced by the unit during period $t$ as well as all of the intermediate inputs used during the period. The components of $y^{t}$ that correspond to outputs are given positive signs while the components of $y^{t}$ that correspond to intermediate inputs are given negative signs. 
production unit. If revenues equal costs in both periods for the production unit, Balk is able to derive a very general exact relationship between the gross output and value added measures of TFP growth; see his Theorem 1. Balk sums up his result in words as follows: if the unit's profits are zero in both periods, then its value added productivity change is equal to its gross output based productivity change times the ratio ${ }^{22}$ of average revenue to average value added for the two periods under consideration. Thus the value added measure of TFP growth will always be larger than the corresponding gross output measure if profits are zero in both periods. Balk also provides an elegant proof of Domar's (1961) aggregation rule, which relates the gross output TFP growth rates of a set of production units to an economy wide measure of TFP growth.

In section 4 of his paper, Balk turns his attention to difference measures of TFP growth. Since many readers will not be familiar with this approach, we will provide an introduction to this topic. ${ }^{23}$

Traditional bilateral index number theory decomposes a value ratio pertaining to the two periods under consideration (say periods 0 and 1 ) into the product of a price index, $\mathrm{P}\left(\mathrm{p}^{0}, \mathrm{p}^{1}, \mathrm{q}^{0}, \mathrm{q}^{1}\right)$, times a quantity index, $\mathrm{Q}\left(\mathrm{p}^{0}, \mathrm{p}^{1}, \mathrm{q}^{0}, \mathrm{q}^{1}\right)$; i.e., we have:

$\mathrm{p}^{1} \cdot \mathrm{q}^{1} / \mathrm{p}^{0} \cdot \mathrm{q}^{0}=\mathrm{P}\left(\mathrm{p}^{0}, \mathrm{p}^{1}, \mathrm{q}^{0}, \mathrm{q}^{1}\right) \mathrm{Q}\left(\mathrm{p}^{0}, \mathrm{p}^{1}, \mathrm{q}^{0}, \mathrm{q}^{1}\right)$

\footnotetext{
${ }^{22}$ Balk calls this ratio the Domar factor; see Domar (1961).

${ }^{23}$ This topic is pursued in much greater depth by Diewert (1992a) (2005) and Balk (2009b).
} 
If there is only one commodity in the aggregate, then the price index $\mathrm{P}\left(\mathrm{p}^{0}, \mathrm{p}^{1}, \mathrm{q}^{0}, \mathrm{q}^{1}\right)$ collapses down to the single price ratio, $\mathrm{p}_{1}{ }^{1} / \mathrm{p}_{1}{ }^{0}$ and the quantity index $\mathrm{Q}\left(\mathrm{p}^{0}, \mathrm{p}^{1}, \mathrm{q}^{0}, \mathrm{q}^{1}\right)$ collapses down to the single quantity ratio, $\mathrm{q}_{1}{ }^{1} / \mathrm{q}_{1}{ }^{0}$. Thus traditional index number theory is based on a ratio principle.

Bennet (1920) and Montgomery (1937) pursued the branch of index number theory where differences replaced the ratios in (12). Thus, they looked for two functions of $4 \mathrm{~N}$ variables, $\quad \Delta \mathrm{P}\left(\mathrm{p}^{0}, \mathrm{p}^{1}, \mathrm{q}^{0}, \mathrm{q}^{1}\right)$ and $\Delta \mathrm{Q}\left(\mathrm{p}^{0}, \mathrm{p}^{1}, \mathrm{q}^{0}, \mathrm{q}^{1}\right)$, which added up to the value difference in the aggregate rather than the value ratio; i.e., these two functions were to satisfy the following equation:

$$
\mathrm{p}^{1} \cdot \mathrm{q}^{1}-\mathrm{p}^{0} \cdot \mathrm{q}^{0}=\Delta \mathrm{P}\left(\mathrm{p}^{0}, \mathrm{p}^{1}, \mathrm{q}^{0}, \mathrm{q}^{1}\right)+\Delta \mathrm{Q}\left(\mathrm{p}^{0}, \mathrm{p}^{1}, \mathrm{q}^{0}, \mathrm{q}^{1}\right)
$$

The two functions, $\Delta \mathrm{P}\left(\mathrm{p}^{0}, \mathrm{p}^{1}, \mathrm{q}^{0}, \mathrm{q}^{1}\right)$ and $\Delta \mathrm{Q}\left(\mathrm{p}^{0}, \mathrm{p}^{1}, \mathrm{q}^{0}, \mathrm{q}^{1}\right)$, are to satisfy certain tests or properties that will allow us to identify $\Delta \mathrm{P}\left(\mathrm{p}^{0}, \mathrm{p}^{1}, \mathrm{q}^{0}, \mathrm{q}^{1}\right)$ as a measure of aggregate price change and $\Delta \mathrm{Q}\left(\mathrm{p}^{0}, \mathrm{p}^{1}, \mathrm{q}^{0}, \mathrm{q}^{1}\right)$ as a measure of aggregate quantity or volume change. Note that if either of these functions is determined, then the other function is also determined. The term indicator of price and quantity change is used to describe $\Delta \mathrm{P}\left(\mathrm{p}^{0}, \mathrm{p}^{1}, \mathrm{q}^{0}, \mathrm{q}^{1}\right)$ and $\Delta \mathrm{Q}\left(\mathrm{p}^{0}, \mathrm{p}^{1}, \mathrm{q}^{0}, \mathrm{q}^{1}\right)$ respectively ${ }^{24}$ (as opposed to the terms price and quantity index which appear in the traditional ratio approach to index number theory).

\footnotetext{
${ }^{24}$ This indicator terminology was introduced by Diewert (1992a; 2005, 349).
} 
Where might one use the difference approach to analyzing value change? A natural home for this approach is in the business and accounting community. The usual ratio approach to the decomposition of value change is not one that the business and accounting community finds natural; a manager or owner of a firm is typically interested in analyzing profit differences rather than ratios. Thus interest centers on decomposing cost, revenue or profit changes into price and quantity (or volume) effects and this is precisely what Balk (2009a) does in section 4 of his paper. Note that if (13) represents a profit decomposition for a production unit, then $\Delta \mathrm{Q}\left(\mathrm{p}^{0}, \mathrm{p}^{1}, \mathrm{q}^{0}, \mathrm{q}^{1}\right)$ can be interpreted as a measure of efficiency improvement for that unit; i.e., it is the difference counterpart to TFP growth in the usual ratio approach to index number theory. ${ }^{25}$ For example, the owner of an oil exploration company will generally be interested in knowing how much of the difference between current period profits over the previous period profits is due to the change in the price of crude oil (this will show up in the $\Delta \mathrm{P}\left(\mathrm{p}^{0}, \mathrm{p}^{1}, \mathrm{q}^{0}, \mathrm{q}^{1}\right)$ term) and how much of the profit change is due to improvements in the operating efficiency of the company (the $\Delta \mathrm{Q}\left(\mathrm{p}^{0}, \mathrm{p}^{1}, \mathrm{q}^{0}, \mathrm{q}^{1}\right)$ term).

Another natural area of application of the difference approach to index number theory is in consumer surplus theory. In this context, the problem is to decompose the change in a consumer's expenditures between two periods into a price change component, $\Delta \mathrm{P}\left(\mathrm{p}^{0}, \mathrm{p}^{1}, \mathrm{q}^{0}, \mathrm{q}^{1}\right)$, plus a quantity change component, $\Delta \mathrm{Q}\left(\mathrm{p}^{0}, \mathrm{p}^{1}, \mathrm{q}^{0}, \mathrm{q}^{1}\right)$, which can be interpreted as a constant dollar measure of utility change. This line of research was

\footnotetext{
${ }^{25}$ See Diewert $(2005 ; 353)$ for this interpretation of $\Delta \mathrm{Q}\left(\mathrm{p}^{0}, \mathrm{p}^{1}, \mathrm{q}^{0}, \mathrm{q}^{1}\right)$. However, the basic idea can be traced back to the early accounting and industrial engineering literature; see Harrison (1918; 275).
} 
started by Marshall (1890) and Bennet (1920) and continued by Hotelling( 1938; 253254), Hicks (1941-42; 134) (1945-46) and Harberger (1971). This second application of the difference approach to index number theory is pursued by Diewert and Mizobuchi (2009) and we will describe their contribution in more detail in the following section.

In section 4 of his paper, Balk (2009a) establishes a remarkably simple result using the difference approach to describing the growth in efficiency of a production unit over the two periods under consideration: the value added based TFP indicator of TFP growth is exactly equal to the corresponding gross output based TFP indicator of TFP growth. Thus there is no need for Domar factors when using the difference approach to measuring the growth of efficiency!

In section 5 of his paper, Balk uses the continuous time Divisia approach to the measurement of TFP growth (rather than the use of discrete time indexes) and establishes essentially the same results as he established in section 3; i.e., under certain assumptions, he shows that value added TFP growth is equal to the Domar factor times gross output TFP growth.

In section 6, Balk again uses a continuous time framework but in this section, he introduces a production function and assumes competitive cost minimizing behavior on the part of the production unit and he also assumes that the production unit maximizes value added taking prices as fixed. He then looks at a cost function based measure of technical progress and compares it to a value added function based measure of technical 
progress. He again finds a Domar type factor relating the two measures of technical progress. In the remainder of section 6, Balk makes various assumptions about competitive behavior and the structure of technical progress in order to obtain generalizations of the results of Solow (1957), Jorgenson and Griliches (1967) and Denny, Fuss and Waverman (1981) relating TFP growth (both gross output and value added) to (path independent) measures of technical progress. Balk finds that path independency of the gross output based TFP index requires that the technology exhibit Hicks input neutrality, whereas path independency of the value added based TFP index requires Hicks value added neutrality. In Balk’s view, both sets of assumptions on the structure of technology and the nature of technical progress are equally restrictive: they simply imply two numerically different measures of technological change. Balk notes that this state of affairs does not imply a break down of measurement, but it reflects a structural state of affairs. Technological change simply moves the production unit's production possibilities set through time. Measurement means that this movement must be mapped into one dimensional space. There is no unique way to do this.

As has been emphasized by Barnett and Hahm (1994), Barnett and Zhou (1994), and Barnett, Kirova, and Pasupathy (1995), empirical research on financial intermediation that brings together production theory, index number theory, and econometrics in an internally coherent manner is rare. Considering the nature of the current financial crisis, few subjects can be viewed as important as financial intermediation. Townsend and Urzua, in their innovative paper in this special issue, state [regarding contract theory models of financial intermediation and econometric policy 
evaluation] that "our goal in this paper is to bring these two strands of the literature together and discuss the assumptions which allow the researcher to go back and forth between the theory and the data." They consider the large literature on changes in financial policies that affect occupational choices by changing credit constraints and/or changing occupational choice risk conditions. As the authors state in the final sentence of their abstract, "all in all, our objective is to assess the impact of financial intermediation on occupational choices and income." In their paper, they consider theoretically and, with a number of empirical examples, various economic theories, econometric methods, and types of data that are useful in achieving their important objective. Because of the focus on occupational choice, this paper is a least as relevant to consumer theory as to producer theory and admirably uses theory from both sides of the market.

\section{Consumer Theory}

There are three papers in this special issue that look at various measurement problems that are associated with aspects of consumer theory. The first consumer theory paper, by Barnett and de Peretti (2009), deals with the subject that is logically prior to all other empirical applications in consumer theory: existence of aggregates and existence of sectors of the economy. Without existence of admissible clusterings of goods permitting aggregation over quantities and prices and separation of the economy into sectors to lower dimension of models, there are too many quantities and prices to permit empirical 
analysis with the typically small sample sizes available to economists. The admissibility condition permitting clustering together groups of goods as components of aggregates is blockwise weak separability. While there is a long history of research on tests for weak separability, that hypothesis has been resistant to successful testing, as has been shown in Monte Carlo studies, starting with Barnett and Choi (1989).

Weak separability is equivalent to existence of a composite function structure, a subtle hypothesis that is difficult to test by parametric means. While flexible function form specifications have been successful in testing many other hypotheses on functional structure, the imposition of blockwise weak separability on parsimonious flexible functional forms, such as the translog and generalized Leontief, results in loss of flexibility, often to severe degrees, as first shown by Blackorby, Primont, and Russell (1977). ${ }^{26}$ Consequently, tests of weak separability become tests of the joint hypothesis of weak separability and of a very inflexible aggregator function, with the latter subhypothesis being the most likely source of rejection. Other parametric approaches to testing weak separability have been proposed and used, but none have so far been shown to perform well in Monte Carlo studies.

The inherent problems associated with parametric testing of weak separability have resulted in growth of nonparametric approaches, often based upon revealed preference theory, with the seminal papers being Varian $(1982,1983)$, who drew on the earlier work by Afriat (1967) and Diewert (1973). But these tests have similarly

\footnotetext{
${ }^{26}$ However, Diewert and Wales (1995) derived tests for homogeneous weak separability in the production context using the normalized quadratic functional form that were not subject to this inflexibility problem. For a survey of much of the relevant literature in a demand context, see Barnett and Serletis (2008).
} 
performed poorly in Monte Carlo studies, since they have tended to be deterministic tests not coping well with violations of revealed preference theory resulting from noise in the data.

In their paper, Barnett and Peretti introduce seminonparametric testing into this literature. This middle ground approach between parametric and nonparametric approaches solves the problems associated with the earlier approaches. Barnett and Peretti's seminonparametric approach is fully stochastic and is not unflexible under the null. Hence their approach is a direct test of weak separability rather than a composite test embedding a more restrictive hypothesis within the null. By eliminating the bias against acceptance of weak separability inherent in the earlier approaches, Barnett and Peretti’s seminonparametric test is shown to perform well in Monte Carlo testing.

The second consumer theory paper is by Erwin Diewert and Hideyuki Mizobuchi (2009) and it addresses the problem of finding index number formulae (and indicator formulae) that are exact for flexible functional forms for nonhomothetic preferences. Diewert (1976) addressed this problem in the index number context but his exact index number results assumed that the consumer had homothetic preferences for the most part. $^{27}$ Diewert (1992a) also addressed the problem of finding exact indicator formulae in the difference approach to index number theory but in the end, his results followed the example of Weitzman (1988) who assumed that preferences were homothetic. Thus the problem of obtaining indicator formulae which are exact for nonhomothetic preferences remains open and this is the problem that Diewert and Mizobuchi address.

\footnotetext{
${ }^{27}$ Diewert $(1976 ; 122-123)$ did establish two exact results for translog nonhomothetic preferences.
} 
As noted earlier, traditional index number theory is based on ratio concepts. Thus if the consumer's preferences are homothetic (so that they can be represented by a linearly homogeneous utility function), then the family of Konüs (1939) price indexes collapses to a ratio of unit cost functions and the family of Allen (1949) quantity indexes collapses to a ratio of utility functions, where these functions are evaluated at the data of say period 1 in the numerator and the data of period 0 in the denominator. After describing this traditional approach to index number theory, Diewert and Mizobuchi switch to the economic approach pioneered by Hicks (1941-42) (1945-46) which is based on differences. As noted in our discussion of Balk's paper, in the traditional approach to index number theory, a value ratio is decomposed into the product of a price index times a quantity index whereas in the difference approach, a value difference is decomposed into the sum of a price indicator (which is a measure of aggregate price change) plus a quantity indicator (which is a measure of aggregate quantity change). The difference analogue to a theoretical Konüs price index is a Hicksian price variation and the difference analogue to an Allen quantity index is a Hicksian quantity variation such as the equivalent or compensating variation. For normal index number theory, the theoretical Konüs and Allen indexes are defined using ratios of cost functions but in the difference approach to index number theory, the theoretical price and quantity variation functions are defined in terms of differences of cost functions. Both index number formulae and indicator functions are known functions of the price and quantity data pertaining to the two periods under consideration. 
Diewert and Mizobuchi define a given price or quantity indicator function to be strongly superlative if it is exactly equal to a corresponding theoretical price or quantity variation, under the assumption that the consumer has (general) preferences which are dual to a flexible cost function that is subject to money metric utility scaling. As we noted in our discussion of Feenstra, Ma and Rao, the term money metric utility scaling is due to Samuelson (1974) and it is simply a convenient way of cardinalizing a utility function. Diewert and Mizobuchi show that the Bennet (1920) indicator functions are strongly superlative. Their results require that the consumer's preferences be represented by a certain translation homothetic cost function that is a variant of the normalized quadratic cost function introduced by Diewert and Wales (1987).

Diewert and Mizobuchi also show that the aggregation over consumers problem in the difference approach to index number theory is not as difficult as it is when aggregating over consumers using the ratio approach to index number theory. In particular, Diewert and Mizobuchi show that it is possible to exactly measure the arithmetic average of the economy's sum of the individual household equivalent and compensating variations using only aggregate data since this aggregate measure of welfare change is exactly equal to the Bennet quantity indicator using only aggregate quantity data. In other words, the difference approach to the measurement of aggregate price and quantity change has better aggregation properties than the traditional ratio approach. 
Diewert and Mizobuchi also provide economic interpretations for each term in the sum of terms that make up the Bennet price and quantity indicators. The decomposition results developed here are analogues to similar results obtained by Diewert and Morrison (1986) and Kohli (1990) in the traditional approach to index number theory.

Diewert and Mizobuchi conclude their paper by using the difference approach to measure aggregate Japanese consumption and they contrast their results with the results generated by the traditional ratio approach to the measurement of real consumption.

The third paper dealing with measurement problems in the context of consumer theory is by Barnett, Chauvet, and Tierney (2009). Most of the papers in this special issue connect together measurement and theory through the use of, and advancement of, economic index number theory and microeconomic aggregation theory. But there is another tradition that has been growing in importance: the use of state-space econometric modeling with "measurement functions.” In this paper, Barnett, Chauvet, and Tierney integrate the state-space time-series approach with the economic index-number-theoretic approach by using the state-space approach to demonstrate that the aggregation-theoretic Divisia monetary aggregates deviate from their common dynamics with the official atheoretical simple-sum monetary aggregates in ways that have predictive power regarding turning points in the business cycle.

Their state space approach uses a factor model with regime switching. The model separates out the common movements underlying the theoretical and atheoretical 
monetary aggregate indexes, summarized in the dynamic factor, from individual variations in each individual series, captured by the idiosyncratic terms. The idiosyncratic terms and the measurement errors reveal where the monetary indexes differ.

In future research, it could be useful to generalize to explicit treatment of measurement error of component quantities and prices and to incorporation of the Divisia monetary growth-rate variances introduced by Barnett and Serletis (1990) to measure dispersion of growth rates over components of aggregates. In fact the approach used in all of the papers in this special issue could benefit from more explicit treatment of second moments and the consequent possible sources of error in index number theory with data that is potentially subject to errors in the variables.

\section{References}

Afriat, S.N. (1967), The construction of utility functions from expenditure data. International Economic Review 8, 67-77.

Allen, R.G.D. (1949), The economic theory of index numbers. Economica 16, 197-203.

Balk, B.M. (1996), A comparison of ten methods for multilateral international price and volume comparisons. Journal of Official Statistics 12, 199-222. 
Balk, B.M. (2003), The residual: on monitoring and benchmarking firms, industries and economies with respect to productivity. Journal of Productivity Analysis 20, 5-47.

Balk, B.M. (2009a), On the relation between gross-output and value-added based productivity measures: The importance of the Domar factor. Macroeconomic Dynamics, this issue.

Balk, B.M. (2009b), Measuring productivity change without neoclassical assumptions: a conceptual analysis. Chapter 4 in Price and Productivity Measurement: Volume 6-Index Number Theory, W.E. Diewert, B.M. Balk, D. Fixler, K.J. Fox and A.O. Nakamura (eds.), Victoria, Canada: Trafford Press.

Banks, J., R. Blundell and A. Lewbel (1997), Quadratic Engel curves and consumer demand. Review of Economics and Statistics 79, 527-539.

Barnett, W. A. and S. Choi (1989), A Monte Carlo study of tests of blockwise weak separability. Journal of Business and Economic Statistics 7, 363-377.

Barnett, W. A. and J. H. Hahm (1994), Financial firm production of monetary services: a generalized symmetric Barnett variable-profit function approach. Journal of Business and Economic Statistics 12, 33-46. 
Barnett, W.A. and P. de Peretti (2009), Admissible clustering of aggregator components: A necessary and sufficient stochastic semi-nonparametric test for weak separability. Macroeconomic Dynamics, this issue.

Barnett, W. A. and A. Serletis (1990), A dispersion dependency diagnostic test for aggregation error: with applications to monetary economics and income distribution. Journal of Econometrics 43, 5-43. Reprinted in W. A. Barnett and A. Serletis (eds.) The Theory of Monetary Aggregation, 2000, North-Holland, Amsterdam, chapter 9, 5-34.

Barnett, W. A. and A. Serletis (2008), Consumer preferences and demand systems. Journal of Econometrics 147, 210-224.

Barnett, W. A. and G. Zhou (1994), Financial firms' production and supply-side monetary aggregation under dynamic uncertainty. Federal Reserve Bank of St. Louis Review 76, 133-165.

Barnett, W.A., M. Chauvet and H.L.R. Tierney (2009), Measurement error in monetary aggregates: A Markov switching factor approach. Macroeconomic Dynamics, this issue.

Barnett, W. A., M. Kirova, and M. Pasupathy (1995), Estimating policy-invariant deep parameters in the financial sector when risk and growth matter. Journal of Money, Credit, and Banking 27, 1402-1430. 
Bennet, T.L. (1920), The theory of measurement of changes in cost of living. Journal of the Royal Statistics Society 83, 455-462.

Bernard, A.B. and C.I. Jones (1996), Comparing apples to oranges: productivity convergence and measurement across industries and countries. American Economic Review 86(5), 1216-1238.

Blackorby, C., D. Primont, and R. R. Russell (1977), On testing separability restrictions with flexible functional forms. Journal of Econometrics 5, 195-209.

Caves, D.W., L.R. Christensen and W.E. Diewert (1982), Multilateral comparisons of output, input and productivity using superlative index numbers. Economic Journal 92, 73-86.

Deaton, A. and A. Heston (2008), Understanding PPPs and PPP-based national accounts. NBER Working Paper 14499, National Bureau of Economic Research, Cambridge, MA.

Deaton, A.S. and J. Muellbauer (1980), An almost ideal demand system. American Economic Review 70, 312-326. 
Denny, M., M. Fuss and L. Waverman (1981), The measurement and interpretation of Total Factor Productivity in regulated industries, with an application to Canadian telecommunications. pp. 179-218 in Productivity Measurement in Regulated Industries, T.G. Cowing and R.E. Stevenson (eds.), New York: Academic Press.

Diewert, W.E. (1973), Afriat and revealed preference theory. The Review of Economic Studies 40, 419-425.

Diewert, W.E. (1976), Exact and superlative index numbers. Journal of Econometrics 4, 114-145.

Diewert, W.E. (1988), Test approaches to international comparisons. pp. 67-86 in Measurement in Economics: Theory and Applications of Economic Indices, W. Eichhorn (ed.), Heidelberg: Physica-Verlag.

Diewert, W.E. (1992a), Exact and superlative welfare change indicators. Economic Inquiry 30, 565-582.

Diewert, W.E. (1992b), The measurement of productivity, Bulletin of Economic Research 44(3), 163-198.

Diewert, W.E. (1999), Axiomatic and economic approaches to international comparisons. pp. 13-87 in International and Interarea Comparisons of Income, Output and 
Prices, A. Heston and R.E. Lipsey (eds.), Studies in Income and Wealth, Volume 61, Chicago: The University of Chicago Press.

Diewert, W.E. (2005) Index number theory using differences instead of ratios. The American Journal of Economics and Sociology 64:1, 311-360.

Diewert, W.E. (2008), New methodological developments for the International Comparison Program. Discussion Paper 08-08, Department of Economics, University of British Columbia, Vancouver, Canada, V6T 1 Z1.

Diewert, W.E. (2009), Similarity indexes and criteria for spatial linking. Chapter 8 in Purchasing Power Parities of Currencies: Recent Advances in Methods and Applications, D.S. Prasada Rao (ed.), Cheltenham, UK: Edward Elgar, pp. 155176.

Diewert, W.E. and D. Lawrence (2006), Measuring the Contributions of Productivity and Terms of Trade to Australia's Economic Welfare. Report by Meyrick and Associates to the Productivity Commission, Canberra, Australia.

Diewert, W.E. and H. Mizobuchi (2009), "Exact and superlative price and quantity indicators. Macroeconomic Dynamics, this issue. 
Diewert, W.E. and C.J. Morrison (1986) Adjusting output and productivity indexes for changes in the terms of trade. The Economic Journal 96, 659-679.

Diewert, W.E. and A.O. Nakamura (2003) Index number concepts, measures and decompositions of productivity growth. Journal of Productivity Analysis 19, 127159.

Diewert, W.E. and T.J. Wales (1987) Flexible functional forms and global curvature conditions. Econometrica 55, 43-68.

Diewert, W.E. and T.J. Wales (1995), Flexible functional forms and tests of homogeneous separability. Journal of Econometrics 67, 259-302.

Domar, E.D. (1961), On the measurement of technological change. The Economic Journal 71, 709-721.

Feenstra, R.C., H. Ma and D.S. Prasada Rao (2009), Consistent comparisons of real incomes across time and space. Macroeconomic Dynamics, this issue.

Fisher, I. (1922), The Making of Index Numbers, Houghton-Mifflin, Boston.

Geary, R.G. (1958), A note on comparisons of exchange rates and purchasing power between countries. Journal of the Royal Statistical Society Series A 121, 97-99. 
Gini, C. (1931), On the circular test of index numbers. Metron 9:9, 3-24.

Harberger, A.C. (1971), Three basic postulates for applied welfare economics: an interpretive essay. The Journal of Economic Literature 9, 785-797.

Harrison, G.C. (1918), Cost accounting to aid production, Part I. Industrial Management 56, 273-282.

Hicks, J.R. (1941-42), Consumers' surplus and index numbers. The Review of Economic Studies 9, 126-137.

Hicks, J.R. (1945-46), The generalized theory of consumers' surplus. The Review of Economic Studies 13, 68-74.

Hill, T.P. (2007), ICP 2003-2006 Handbook. Chapters 11-15, Washington D.C.: The World Bank. http://siteresources.worldbank.org/ICPINT/Resources/Ch11.doc

Hill, R.J. (1997), A taxonomy of multilateral methods for making international comparisons of prices and quantities. Review of Income and Wealth 43(1), 49-69.

Hill, R.J. (1999), Comparing price levels across countries using minimum spanning trees. The Review of Economics and Statistics 81, 135-142. 
Hill, R.J. (2001), Measuring inflation and growth using spanning trees. International Economic Review 42, 167-185.

Hill, R.J. (2004), Constructing price indexes across space and time: the case of the European Union. American Economic Review 94, 1379-1410.

Hill, R.J. and T.P. Hill (2009), Recent developments in the international comparison of prices and real output. Macroeconomic Dynamics, this issue.

Hotelling, H. (1938), The general welfare in relation to problems of taxation and of railway and utility rates. Econometrica 6, 242-269.

Inklaar, R. and M.P. Timmer (2009), Productivity convergence across industries and countries: The importance of theory based measurement. Macroeconomic Dynamics, this issue.

Jorgenson, D.W. and Z. Griliches (1967), The explanation of productivity change. Review of Economic Studies 34, 249-283.

Khamis, S.H. (1972), A new system of index numbers for national and international purposes. Journal of the Royal Statistical Society Series A 135, 96-121. 
Kohli, U. (1990), Growth accounting in the open economy: parametric and nonparametric Estimates. Journal of Economic and Social Measurement 16, 125-136.

Konüs, A.A. (1939), The problem of the true index of the cost of living. Econometrica 7, 10-29.

Marshall, A. (1890), Principles of Economics. London: The Macmillan Co.

Montgomery, J.K. (1937), The Mathematical Problem of the Price Index. Orchard House, Westminster: P.S. King \& Son.

Neary, J.P. (2004), Rationalizing the Penn World Tables: true multilateral indices for international comparisons of real income. The American Economic Review 94, 1411-1428.

Samuelson, P.A. (1974), Complementarity-an essay on the $40^{\text {th }}$ anniversary of the Hicks-Allen revolution in demand theory. The Journal of Economic Literature 12, 1255-1289.

Solow, R.M. (1957), Technical change and the aggregate production function”, Review of Economics and Statistics 39, 312-320. 
Townsend, R.M. and S.S. Urzua (2009), Measuring the impact of financial intermediation: Linking contract theory to econometric policy evaluation. Macroeconomic Dynamics, this issue.

Varian, H. (1982), The nonparametric approach to demand analysis, Econometrica 50, 945-973.

Varian, H. (1983), Non-parametric tests of consumer behavior. Review of Economic Studies 50, 99-110.

Weitzman, M.L. (1988), Consumer's surplus as an exact approximation when prices are appropriately deflated. The Quarterly Journal of Economics 102, 543-553.

World Bank (2008), 2005 International Comparison Program: Tables of Final Results. preliminary draft, Washington D.C., February. http://siteresources.worldbank.org/ICPINT/Resources/ICP_final-results.pdf 